\title{
PENGGUNAAN METODE JALUR KRITIS PADA MANAJEMEN PROYEK (STUDI KASUS: PT. TREND COMMUNICATIONS INTERNATIONAL)
}

\author{
Nurvelly Rosanti ${ }^{1 *}$, Erwin Setiawan ${ }^{2}$, Asti Ayuningtyas ${ }^{3}$ \\ ${ }^{1,2,3}$ Teknik Informatika,Fakultas Teknik Universitas Muhammadiyah Jakarta \\ *Email : nurvelly.rosanti@ftumj.ac.id
}

Diterima: 31 Juli 2015

Direvisi: 14 September 2015

Disetujui: 21 Oktober 2015

\begin{abstract}
ABSTRAK
Manajemen proyek merupakan bagian yang penting dalam proyek pengembangan perangkat lunak, karenanya penggunaan teknologi untuk mendukung efektifitas dan efisiensi dari manajemen proyek. PT. Trend Communications International (TRENDcom) merupakan sebuah perusahaan penyedia jasa Project Management Office (PMO) dengan menawarkan keahlian mereka dalam mengelola proyek-proyek IT. Salah satu masalah yang mereka hadapi adalah dalam mengelola waktu. Keterlambatan proyek disebabkan oleh berbagai faktor yang berhubungan dengan manusia, proses dan teknologi. Dari aspek teknologi, tidak adanya aplikasi yang mampu menyediakan informasi bagi manajer proyek dan timnya tentang aktifitas yang berpotensi menyebabkan keterlambatan proyek secara keselurahan, serta tugas yang sering terlewatkan tenggat waktunya merupakan penyebabnya. Dengan menggunakan Metode Jalur Kritis, sebuah aplikasi telah dibangun untuk menyelesaikan permasalahan tersebut. Aplikasi tersebut dapat menunjukan informasi jalur kritis atau jalur yang aktifitasnya perlu dimonitor dengan seksama sehingga dapat diprioritaskan dan fitur pengingat untuk aktifitas yang tenggat waktunya sudah dekat.
\end{abstract}

Kata Kunci: Manajemen Proyek, Critical Path Method/Metode Jalur Kritis, Manajemen Waktu

\begin{abstract}
Project Management has been an important part of software development projects, therefore the use of technology to endorse effectiveness and efficiency of Project Management is a crucial aspect. PT. Trend Communications Internation (TRENDcom) is a company providing Project Management Office (PMO) service. Their main service is to provide expertise in managing Information Technology projects. One of the big issues they are facing is managing timeline. Late of delivery is caused by people, process and technology reasons. Technology-wise, the absence of application to let project manager and his PMO team the important activities that will cause delay on overall progress as well as the lack of reminder for their due project activities. Using Critical Path Method, an application is developed to address the issues. The application managed to give information of activities in a schedule which has big impact on overall delivery timeline and to provide reminder of due activities.
\end{abstract}

Keywords: Project Management, Critical Path Method, Scheduling, Time Management 


\section{PENDAHULUAN}

Semakin berkembangnya kemajuan teknologi informasi meningkatkan penggunaan teknologi tersebut di dunia bisnis. Maka dalam rangka penggunaan teknologi informasi, banyak proyek-proyek teknologi informasi dijalankan baik itu proyek untuk pengadaan perangkat keras maupun untuk pembuatan perangkat lunak atau gabungannya.

Manajemen proyek untuk implementasi proyek teknologi informasi menjadi hal yang penting agar proyek-proyek tersebut dapat terlaksana dengan baik dan mencapai hasil semaksimal mungkin dengan tetap memperhatikan penggunaan waktu dan biaya selagi mempertahankan kualitas (mutu) proyek tersebut. Manajemen proyek mencakup banyak aspek seperti pengelolaan lingkup kerja (Scope Management), manajemen waktu (Time Management), manajemen biaya (Cost Management), manajemen kualitas dan sebagainya. Setiap aspek dalam pelaksanaan manajemen proyek memiliki kendalanya masing-masing.

PT. Trend Communications International (PT. TRENDcom) adalah sebuah perusahaan yang bergerak di bidang konsultasi Teknologi Informasi dengan spesifikasi di bidang Telekomunikasi. Salah satu jasa yang ditawarkan adalah PMO (Project Management Office) bagi operator-operator telekomunikasi dalam melakukan implementasi proyek teknologi informasi.

Setiap proyek mengharuskan PMO PT. TRENDcom memberikan deliverable atas pelaksanaan manajemen proyek yang dilakukan. Meskipun setiap proyek memiliki keunikan tersendiri, secara umum deliverable tim PMO untuk pelaksanaan manajemen proyek mencakup area Project Planning, Schedule and Change Control, Quality Control, Communication Management, Risk Identification and Control serta Expert Assistance. Deliverable tersebut merupakan indikator kesuksesan manajemen proyek yang dilakukan.

Setiap proyek memiliki indikator beragam untuk deliverable dari area Schedule Control, namun secara umum indikator utama dari Schedule Control ini adalah tenggat waktu proyek tercapai dan setiap perubahan tenggat waktu proyek tercatat dan terdokumentasi dengan baik. Berdasarkan wawancara dengan manajer program (sekumpulan proyek), manajer proyek dan beberapa anggota tim PMO PT. TRENDcom, diketahui bahwa PMO menghadapi kendala untuk memberikan deliverable yang memuaskan untuk area Schedule Control ini. Tidak ada proyek yang tepat waktu sesuai dengan perencanaan pertama. Sekitar 2 dari 5 proyek selesai sesuai dengan perencanaan kedua dan ketiga. Sisanya memerlukan beberapa kali revisi penjadwalan. Keterlambatan proyek merugikan banyak pihak baik itu kerugian yang dapat dihitung maupun yang tidak dapat dihitung. Kerugian material atau kerugian yang dapat dihitung terjadi karena membengkaknya biaya yang perlu dikeluarkan untuk membayar tenaga profesional/ahli yang diperlukan dalam menjalankan proyek, biaya denda jika ada kontrak dengan pihak ketiga yang terikat waktu, dan lain sebagainya. Kerugian nonmaterial atau yang tidak dapat dihitung misalnya time-to-market yang terlambat sehingga mengakibatkan kalah persaingan dengan kompetitor, motivasi kerja yang menurun dari tim proyek karena tekanan yang semakin tinggi dan waktu kerja yang tidak kujung selesai, dan lain sebagainya.

Meskipun secara kontrak dengan klien yang menggunakan jasa PMO biasanya tidak ada penalti atas keterlambatan proyek selama itu tidak menimbulkan biaya tambahan pada aspek lainnya seperti sumber daya manusia atau lisensi aplikasi, sehingga tidak ada target eksplisit mengenai ketepatan dalam memenuhi tenggat waktu. Namun secara internal PT. TRENDcom, demi meningkatkan mutu jasa, ditargetkan $100 \%$ dari proyek-proyek yang dijalankan dapat diselesaikan, $70 \%$ diselesaikan sesuai dengan tenggat waktu pada perencanaan awal dan sisanya selesai maksimal dengan tenggat waktu 2 kali perencanaan awal proyek (misalnya periode proyek awalnya direncanakan 1 tahun, maka maksimal toleransi untuk keterlambatan proyek adalah 2 tahun).

Keterlambatan penyelesaian proyek ini harus dikurangi bahkan dihilangkan untuk dapat memenuhi target internal PT. TRENDcom dan juga menghindari kerugian-kerugian yang tidak diinginkan. Untuk itu penggunaan metode jalur kritis digunakan agar dapat menjawab permasalahan yang ada berkaitan dengan pencegahan keterlambatan tersebut. 
Nurvelly Rosanti, Erwin Setiawan, Asti Ayuningtyas : Penggunaan Metode Jalur Kritis Pada Manajemen Proyek (Studi Kasus: Pt. Trend Communications International)

Jurnal Teknologi. 8 (1) pp 23-30 @ 2016

\section{LANDASAN TEORI \\ Manajemen Proyek}

Proyek adalah sebuah kumpulan aktivitas yang bersifat sementara (temporary) yang dirancang untuk mencapai suatu hasil yang unik (tidak bersifat operasional atau terus menerus). Karena proyek bersifat sementara, maka proyek memiliki batasan ruang lingkup dan sumber daya. Untuk itu diperlukan suatu pengaturan atau manajemen terhadap batasanbatasan proyek tersebut dengan tetap berusaha mencapai tujuan proyek (Project Management Instititute, 2013).

Manajemen proyek adalah penerapan pengetahuan (knowledge), keterampilan (skill), alat (tools) dan teknik (techniques) terhadap aktifitas proyek dalam rangka memenuhi atau melebihi ekspektasi pemegang kepentingan proyek terhadap kebutuhan dan harapan dari hasil proyek tersebut.

\section{Metode Jalur Kritis (Critical Path Method)}

Metode Jalur Kritis atau critical path method (CPM) adalah sebuah teknik pemodelan proyek yang dikembangkan oleh Morgan R. Walker dari DuPont dan James E. Kelley dari Remington Rand di akhir tahun 1950.

Metode ini mampu mengidentifikasi jalur kritis pada sekumpulan aktifitas yang telah ditentukan ketergantungan antar aktifitasnya. Aktifitas adalah sebuah tugas spesifik yang memiliki satu hasil yang dapat diukur yang memiliki durasi pengerjaannya. Jalur kritis adalah sekumpulan aktifitas yang saling bergantung yang harus selesai sesuai dengan waktu yang direncanakan karena jika tidak maka keseluruhan waktu pengerjaan proyek akan terlambat. Dengan kata lain waktu yang diperlukan oleh jalur kritis adalah waktu yang diperlukan sebuah proyek untuk selesai. Sebuah proyek dapat memiliki lebih dari satu jalur kritis. Mengingat pentingnya setiap aktifitas di jalur kritis untuk terlaksana tepat waktu, maka aktifitas-aktifitas tersebut perlu dimonitor lebih khusus (Olivier de Weck, 2012).

\section{Keuntungan Penggunaan Metode Jalur Kritis}

Kegunaan Metode Jalur Kritis pada implementasi perencanaan sebuah proyek adalah sebagai berikut (L. Baker, Samuel: 2004):

a. Membantu memberikan informasi seberapa lama sebuah proyek memerlukan waktu b. Mengidentifikasi aktifitas-aktifitas mana saja yang ada pada jalur kritis dan perlu dimonitor dengan seksama

c. Memberikan gambaran tentang kemungkinan sebuah proyek dapat dijalankan lebih cepat atau tidak

\section{Diagram}

Diagram yang dapat digunakan dalam menggambarkan aktifitas proyek dengan metode jalur kritis ini adalah Activity-on-node yang diambil dari Precedence Diagram. Dalam Precedence Diagram garis menunjukan dependency atau ketergantungan antar aktifitas dan node sebagai aktifitasnya.

Tabel 1. Simbol Precedence Diagram

\begin{tabular}{|l|l|}
\hline Simbol & \multicolumn{1}{|c|}{ Penjelasan } \\
\hline$\longrightarrow$ & $\begin{array}{l}\text { Hubungan/relationship } \\
\text { aktifitas/task }\end{array}$ \\
\hline & Aktifitas/Task \\
\hline
\end{tabular}

\section{Tahapan Penerapan Metode Jalur Kritis}

Tahapan yang dilakukan dalam metode jalur kritis adalah sebagai berikut

a. Tentukan aktifitas-aktifitas proyek dan identifikasi ketergantungan (dependency) antar aktifitas tersebut. Aktifitas yang hanya dapat dilakukan setelah aktifitas tertentu selesai dilakukan disebut predecessor dan aktifitas yang menjadi prasyarat itu disebut successor. Contoh dapat dilihat di tabel 2.3 berikut ini.

Tabel 2. Contoh Aktifitas Proyek

\begin{tabular}{|c|c|c|c|}
\hline $\begin{array}{c}\text { Activity } \\
\text { ID }\end{array}$ & $\begin{array}{c}\text { Durat } \\
\text { ion }\end{array}$ & $\begin{array}{c}\text { Success } \\
\text { or }\end{array}$ & $\begin{array}{c}\text { Predece } \\
\text { ssor }\end{array}$ \\
\hline A & 6 & & C \\
\hline B & 3 & & D,F \\
\hline C & 5 & A & G \\
\hline D & 2 & B & F \\
\hline E & 2 & D, F & H \\
\hline F & 1 & B & E \\
\hline G & 3 & C & H \\
\hline H & 2 & E, G & \multicolumn{1}{|c}{} \\
\hline
\end{tabular}

b. Tentukan durasi (duration) untuk setiap aktfitas

c. Tentukan waktu tercepat untuk memulai (early start), waktu tercepat untuk selesai (early finish) serta waktu paling akhir untuk memulai dan selesai tanpa mengubah 
keseluruhan waktu proyek (late start dan late finish).

Early start adalah waktu tercepat sebuah aktifitas dapat dimulai setelah predecessornya selesai dilakukan. Early finish adalah waktu tercepat aktifitas tersebut selesai, dalam hal ini berarti early start + duration. Menentukan early start dimulai dari start lalu aktifitas paling awal. Early start untuk aktifitas pertama (yang tidak memiliki predecessor) adalah 0 dan early finishnya adalah 0+duration aktifitas tersebut. Mencari ES dan EF dimulai dari start dan dirunut hingga ke aktifitas terakhir sebelum finish. EF dari sebuah aktifitas adalah ES untuk aktifitas sucessornya. Jika ada dua aktifitas sebelum sebuah sucecessor, maka diambil EF yang paling besar. Sebagai contoh, jika aktifitas A adalah aktifitas yang tidak memiliki predecessor dan memiliki durasi 6, maka early start (ES) adalah 0 dan early finish (EF) adalah $0+6$ atau 6 .

\begin{tabular}{|c|c|c|}
\hline $\begin{array}{c}\text { Early } \\
\text { Start } \\
\text { (ES) }\end{array}$ & $\begin{array}{c}\text { Activity } \\
\text { ID }\end{array}$ & $\begin{array}{c}\text { Early } \\
\text { Finish } \\
\text { (EF) }\end{array}$ \\
$\mathbf{0}$ & $\mathbf{A}$ & $\mathbf{6}$ \\
\hline $\begin{array}{c}\text { Late } \\
\text { Start } \\
\text { (LS) }\end{array}$ & Duration & $\begin{array}{c}\text { Late } \\
\text { Finish } \\
\text { (LF) }\end{array}$ \\
& $\mathbf{6}$ & \\
\hline
\end{tabular}

Gambar 1. Contoh Diagram Activity-on-node dengan Early Start dan Early Finish

Sedangkan late start (LS) adalah waktu paling lambat sebuah aktifitas dapat dimulai tanpa mengubah target waktu akhir dari keseluruhan proyek. Sementara late finish (LF) adalah waktu paling lambat sebuah aktifitas harus selesai tanpa mengubah target waktu akhir. LS adalah LF - duration. Jika saat mencari ES dan EF dimulai dari start dan dirunut hingga ke aktifitas terakhir sebelum finish (aktifitas yang tidak memiliki successor), pada LS dan LF dirunut dari aktifitas terakhir mundur hingga start karena patokannya adalah target waktu terakhir dari proyek. Sehinggal LF untuk aktifitas terakhir adalah waktu keselurah proyek akan berakhir, dan LSnya adalah LF - duration. LS dari sebuah aktifitas adalah LF untuk aktifitas predecessornya. Jika ada dua aktifitas sebelum sebuah predecessor, maka diambil LS yang paling kecil. Sebagai contoh jika aktifitas
$\mathrm{H}$ adalah aktifitas yang tidak memiliki successor dan memiliki durasi 2 dan diketahui bahwa target akhir proyek adalah 16, maka late finish (LF) adalah 16 dan late start (LS) adalah 16 - 2 atau 14.

\begin{tabular}{|c|c|c|}
\hline $\begin{array}{l}\text { Early } \\
\text { Start } \\
\text { (ES) }\end{array}$ & $\begin{array}{c}\text { Activity } \\
\text { ID } \\
\\
\text { H }\end{array}$ & $\begin{array}{c}\text { Early } \\
\text { Finish } \\
\text { (EF) }\end{array}$ \\
\hline $\begin{array}{l}\text { Late } \\
\text { Start } \\
\text { (LS) }\end{array}$ & Duration & $\begin{array}{l}\text { Late } \\
\text { Finish } \\
\text { (LF) }\end{array}$ \\
\hline 14 & 2 & 16 \\
\hline
\end{tabular}

Gambar 2. Contoh Diagram Activity-on-node dengan Late Start dan Late Finish

Float atau slack adalah toleransi waktu telat sebuah aktifitas untuk dimulai dari early start (ES) tetapi tidak mengubah tenggat waktu keseluruhan proyek. Aktifitas-aktifitas pada jalur kritis memiliki float atau slack 0 .

Sehingga dari tabel aktifitas di atas, dapat dibuat diagram jaringan sebagai berikut.

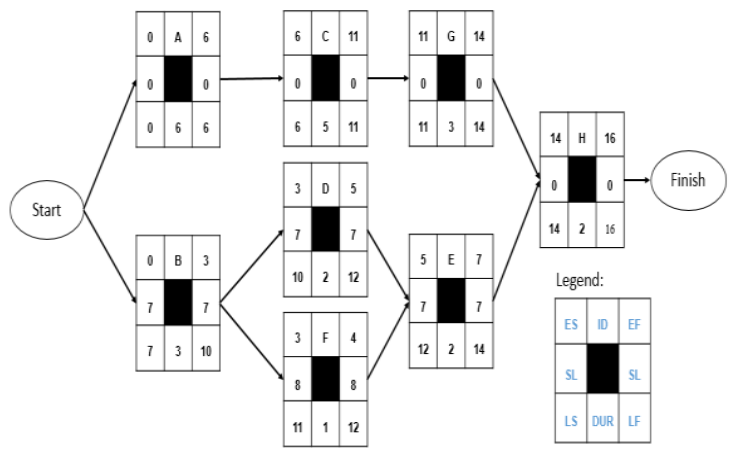

Gambar 3. Contoh Diagram Activity-on-node Pada Penjadwalan dengan Metode Jalur Kritis

\section{Keterangan:}

ES: Early Start

ID: Activity ID

EF: Early Finish

SL: Slack time

LS: Late Start

DUR: Duration

\section{LF: Late Finish}

Dari gambar tersebut maka didapatkan jalur A-C-G-H, B-D-E-H, dan B-F-E-H. Jalur kritis pada diagram tersebut adalah A-C-G-H, ditandai dengan slack time setiap aktifitasnya 0 dan waktu yang diperlukan jalur tersebut (16) adalah waktu terpanjang serta merupakan waktu keseluruhan proyek tersebut. 


\section{PERANCANGAN SISTEM}

\section{Analisis Sistem Berjalan}

Sistem berjalan atau existing system yang akan dianalisa adalah sistem penjadwalan yang dilakukan oleh tim PMO atau Project Management Service. Prosedur penjadwalan aktifitas proyek pada sistem berjalan dilakukan beberapa tahap.

1. Prosedur yang dilakukan oleh manajer proyek:

a. Manajer proyek mengidentifikasi aktifitas yang akan dilakukan di dalam pelaksanaan proyek berdasarkan kebutuhan proyek dan permintaan dari klien/user.

b. Manajer proyek memubuat project plan. Project milestones dan aktifitas proyek yang berhubungan dengan kontrak akan didokumentasikan ke dalam bentuk Microsoft Project Plan (MPP). Project plan tersebut akan digunakan sebagai acuan untuk setiap anggota PMO dalam menjalankan aktifitas/tugas proyek. Selain informasi tenggat waktu, setiap milestone juga memiliki status yang menjelaskan perkembangan atau progress aktifitas/tugas tersebut.

c. Manajer proyek menerima status update untuk setiap aktifitas/tugas dari anggota tim PMO.

d. Manajer proyek memberikan laporan rutin kepada stakeholder mengenai kemajuan proyek.

2. Prosedur yang dilakukan oleh anggota tim PMO:

3.1 Setiap anggota PMO meng-update status perkembangan dari aktifitas proyek. Status setiap aktifitas/tugas akan secara rutin diperbaharui di Project Plan tersebut sebagai bahan laporan perkembangan proyek rutin. Setiap anggota PMO dan pihak yang berkepentingan memiliki akses terhadap Project Plan yang sudah diperbaharui tersebut. Project plan tersebut adalah file MPP yang diunggah ke shared directory.

3.2 Jika ada tugas yang merupakan bagian dari tugas di project plan, maka tugas-tugas tersebut akan didokumentasikan ke dalam spreadsheet oleh masing-masing anggota tim PMO untuk kebutuhan areanya masing-masing. Tugas tersebut tidak dimonitor di project plan, agar project plan tidak menjadi terlalu detail.

\section{Sistem Usulan}

Sebagai solusi atas permasalahan pada sistem berjalan maka diusulkan sistem penjadwalan yang dapat diakses oleh setiap pihak yang berkepentingan. Sistem tersebut akan memiliki fitu sebagai berikut:

Tabel 3. Solusi Usulan Terhadap Permasalah di Sistem Berjalan

\begin{tabular}{|c|c|c|c|}
\hline No & Solusi & Deskripsi & $\begin{array}{l}\text { Kode } \\
\text { Masal } \\
\text { ah }\end{array}$ \\
\hline 1 & $\begin{array}{l}\text { Fitur yang } \\
\text { menampilka } \\
\mathrm{n} \text { informasi } \\
\text { mengenai } \\
\text { jalur kritis }\end{array}$ & $\begin{array}{l}\text { Jalur kritis atau } \\
\text { sekumpulan } \\
\text { aktifitas yang } \\
\text { saling } \\
\text { bergantung yang } \\
\text { harus selesai } \\
\text { sesuai dengan } \\
\text { waktu yang } \\
\text { direncanakan } \\
\text { karena jika tidak } \\
\text { maka } \\
\text { keseluruhan } \\
\text { waktu akan } \\
\text { pengerjaan } \\
\text { proyek akan } \\
\text { terlambat, akan } \\
\text { dimunculkan } \\
\text { setelah input } \\
\text { jadwal } \\
\text { dilakukan oleh } \\
\text { manajer proyek. } \\
\text { Sehingga } \\
\text { manajer proyek } \\
\text { dan tim PMO } \\
\text { terkait dapat } \\
\text { melakukan } \\
\text { monitoring yang } \\
\text { lebih pada } \\
\text { aktifitas-aktifitas } \\
\text { tersebut. }\end{array}$ & M01 \\
\hline 2 & $\begin{array}{l}\text { Dapat } \\
\text { diakses } \\
\text { secara } \\
\text { online }\end{array}$ & $\begin{array}{l}\text { Dengan adanya } \\
\text { akses pihak } \\
\text { yang } \\
\text { berkepentingan } \\
\text { terhadap jadwal, } \\
\text { maka } \\
\text { pembaharuan }\end{array}$ & M02 \\
\hline
\end{tabular}




\begin{tabular}{|c|c|c|c|}
\hline No & Solusi & Deskripsi & $\begin{array}{l}\text { Kode } \\
\text { Masal } \\
\text { ah }\end{array}$ \\
\hline & & $\begin{array}{l}\text { atau peng- } \\
\text { update-an status } \\
\text { perkembangan } \\
\text { sebuah aktifitas } \\
\text { akan lebih cepat. } \\
\text { Hal ini akan } \\
\text { mempermudah } \\
\text { pengambilan } \\
\text { tindakan jika } \\
\text { diketahui bahwa } \\
\text { suatu aktifitas } \\
\text { tidak akan } \\
\text { memenuhi target } \\
\text { tenggat } \\
\text { waktunya }\end{array}$ & \\
\hline 3 & $\begin{array}{l}\text { Pengingat } \\
\text { tugas }\end{array}$ & $\begin{array}{l}\text { Setiap aktifitas } \\
\text { akan memiliki } \\
\text { fitur pengingat. } \\
\text { Dengan } \\
\text { mengaktifkan } \\
\text { fitur pengingat } \\
\text { ini, maka setiap } \\
\text { penanggung } \\
\text { jawab tugas atau } \\
\text { PIC (Person in } \\
\text { Charge) } \\
\text { diharapkan lebih } \\
\text { sigap dalam } \\
\text { menyelesaikan } \\
\text { tugasnya. }\end{array}$ & M03 \\
\hline
\end{tabular}

Konsep metode jalur kritis yang akan diterapkan adalah sebagai berikut.

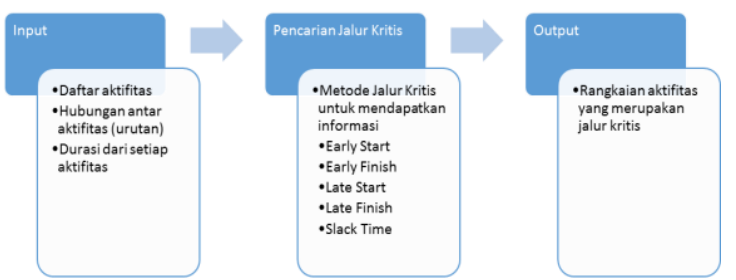

Gambar 5. Konsep Metode Jalur Kritis

Berikut adalah diagram alur perhitungan jalur kritisnya.

Berdasarkan daftar aktifitas tersebut penghitungan jalur kritis akan dilakukan. Penghitungan ini akan menghasilkan early start, early finish, late start, late finish dan slack time yang diperlukan untuk mengidentifikasikan jalur kritis.

Early start adalah waktu tercepat sebuah aktifitas dapat dimulai setelah predecessornya selesai dilakukan. Early finish adalah waktu tercepat aktifitas tersebut selesai, dalam hal ini berarti early start + duration. Sedangkan late start (LS) adalah waktu paling lambat sebuah aktifitas dapat dimulai tanpa mengubah target waktu akhir dari keseluruhan proyek. Sementara late finish (LF) adalah waktu paling lambat sebuah aktifitas harus selesai tanpa mengubah target waktu akhir. LS adalah LF duration.

Float atau slack adalah toleransi waktu telat sebuah aktifitas untuk dimulai dari early start (ES) tetapi tidak mengubah tenggat waktu keseluruhan proyek. Aktifitasaktifitas pada jalur kritis memiliki float atau slack 0.

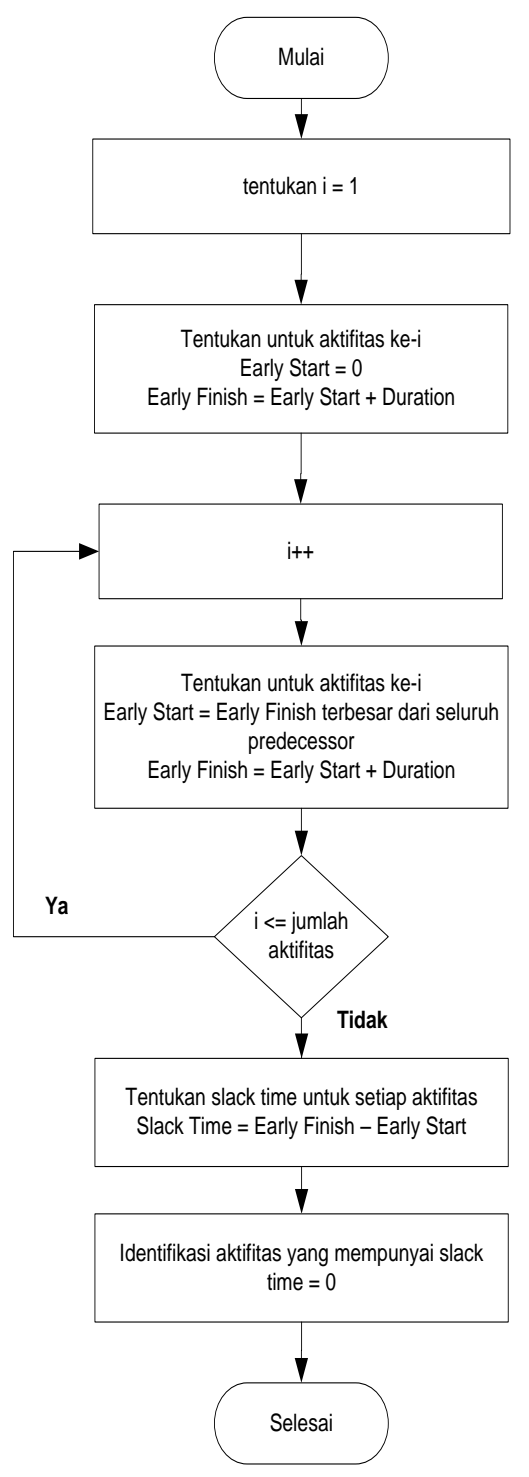

Gambar 6. Diagram Alur Metode Jalur Kritis 
Nurvelly Rosanti, Erwin Setiawan, Asti Ayuningtyas : Penggunaan Metode Jalur Kritis Pada Manajemen Proyek (Studi Kasus: Pt. Trend Communications International)

Jurnal Teknologi. 8 (1) pp 23-30 @ 2016

\section{Hasil dan Implementasi}

Validasi Terhadap User Requirement

Fitur yang menampilkan informasi mengenai jalur kritis.

1 Memasukkan informasi mengenai schedule.

\begin{tabular}{|c|c|c|c|c|c|c|c|c|}
\hline \multicolumn{6}{|c|}{ Project Scheduling } & Home & Schedule & Usersetting \\
\hline & & & & \multicolumn{2}{|r|}{ 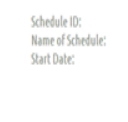 } & \multicolumn{3}{|c|}{ 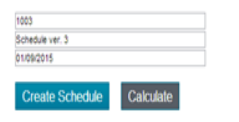 } \\
\hline \multicolumn{9}{|c|}{$\begin{array}{l}\text { Memasukkan aktifitas detail di dalam } \\
\text { grid }\end{array}$} \\
\hline \multicolumn{6}{|c|}{ Project Scheduling } & Home & Schedule & User Setting \\
\hline & & & & \multicolumn{2}{|r|}{ 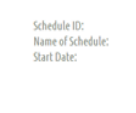 } & \multicolumn{3}{|c|}{ 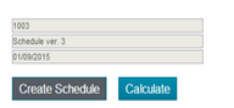 } \\
\hline semente id & Nempryit & 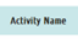 & Dexasions & onatum & mereresur & Aatury omerer & 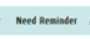 & Natests \\
\hline & 1001 & A & $\cos \alpha$ & 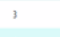 & $\cdot$ & $w$ & . & $+x$ \\
\hline & 1 & - & $\cos \theta$ & ، & womer & (2) & ' & $+*$ \\
\hline (⿻) & 1 & ' & benct & 2 & 10002 & a & . & $+*$ \\
\hline wow & 10004 & 。 & $\cos 0$ & 1 & 10012 & 12 & - & $+x$ \\
\hline 1003 & с⿻上丨⿶凵 & : & oute & ' & (mose & w & & $+*$ \\
\hline wos & 1000 & ; & $\operatorname{cosect}$ & 2 & 19010, & 284 & ' & $+x$ \\
\hline
\end{tabular}

3 Klik tombol Calculate

4 Informasi Jalur Kritis muncul

Fitur yang menampilkan informasi mengenai jalur kritis.
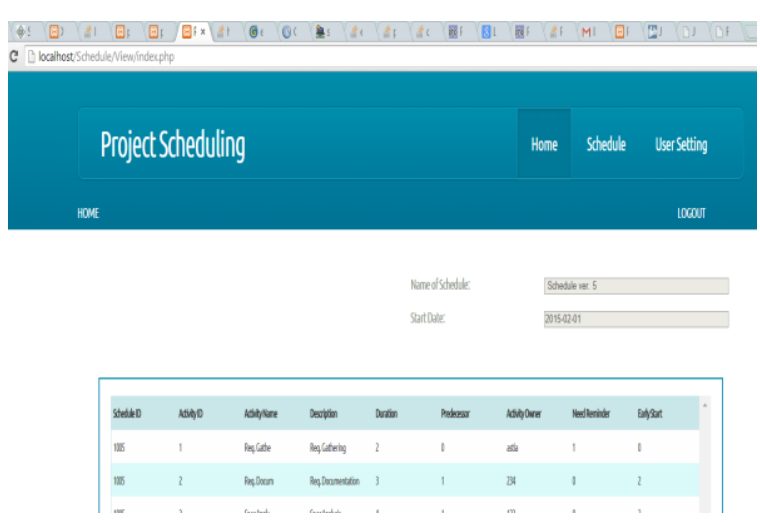

Fitur yang menampilkan informasi mengenai jalur kritis.

a. Pada pembuatan jadwal, aktifitas yang memerlukan reminder diberikan flag 1

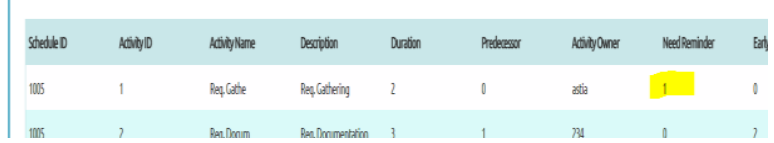

b. Scheduler diatur untuk berjalan harian

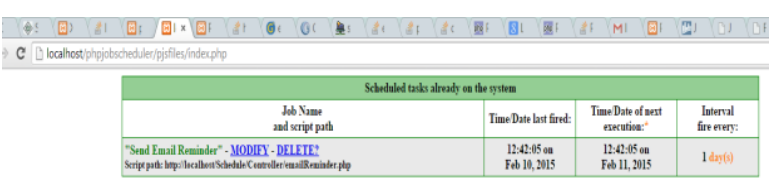

\section{Pengujian Fungsi Pada Sistem}

Pengujian pada halaman login dijelaskan pada tabel berikut ini.
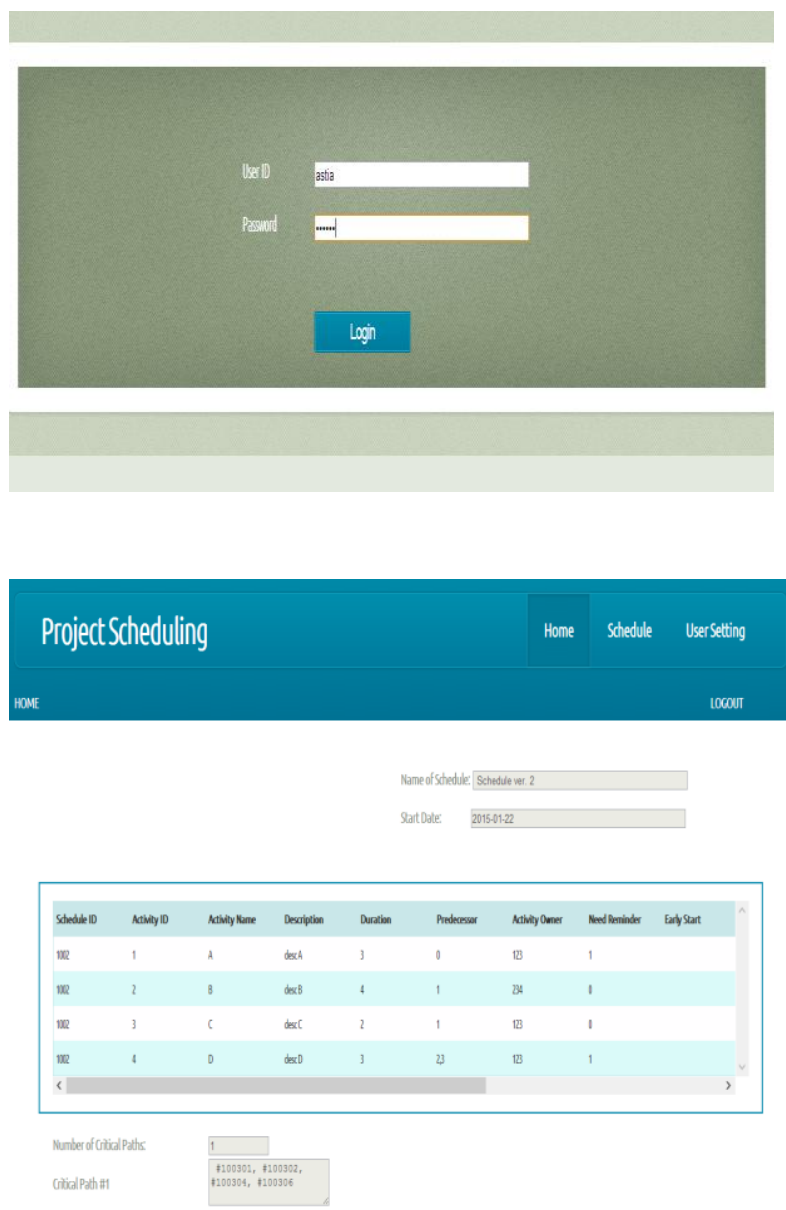

Create Schedule Berhasil

Membuat jadwal dengan memasukkan data-data yang dibutuhkan.

a. Memasukkan informasi mengenai schedule. Klik tombol Create Schedule 


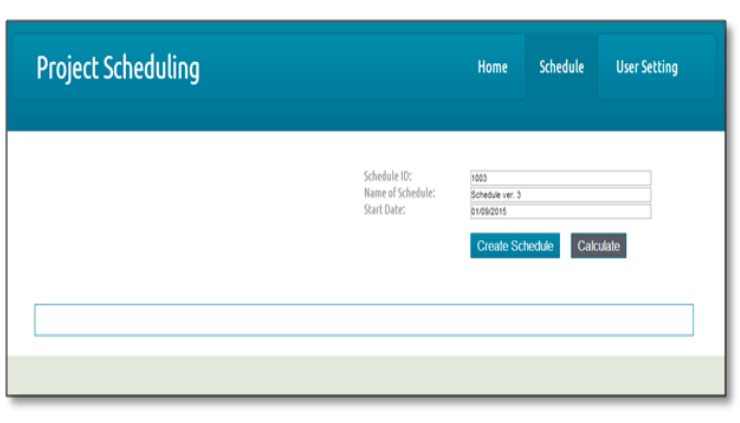

b. Memasukkan aktifitas detail di dalam grid

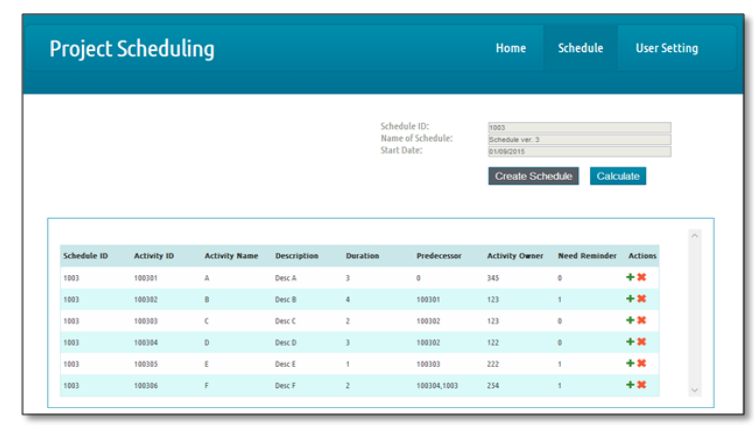

Menggunakan jalur kritis, pembuatan jadwal dilakukan dengan memasukkan daftar aktifitas seperti ditampilkan pada gambar berikut ini.

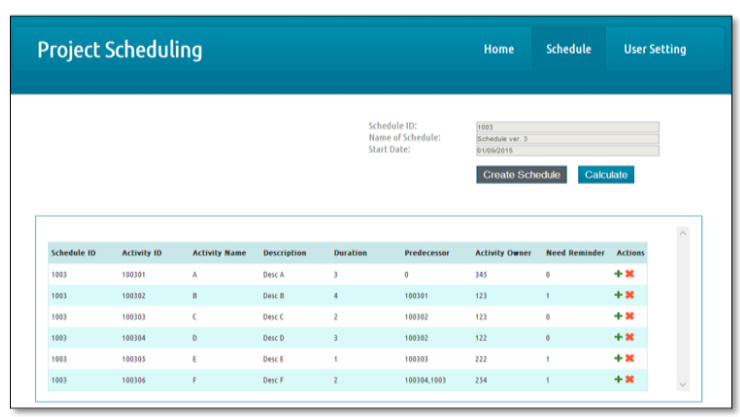

Gambar 7. Jadwal Proyek

Maka jalur kritis akan ditampilkan berdasarkan input daftar aktifitas tersebut.

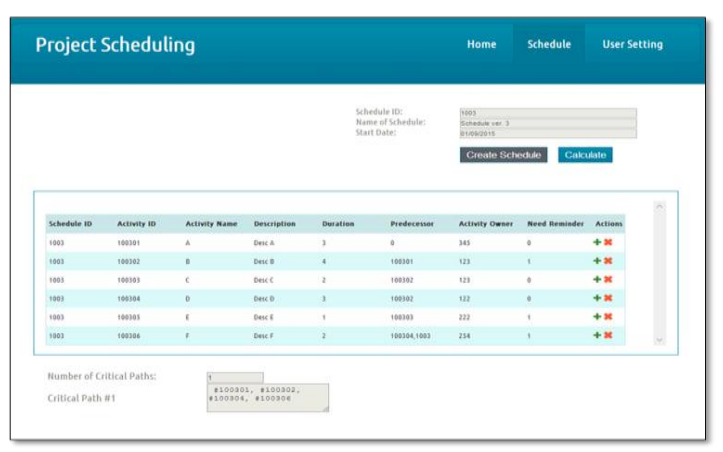

Gambar 8. Jadwal Proyek dan Jalur Kritisnya

\section{KESIMPULAN}

Penelitian ini telah berhasil mengembangkan aplikasi dengan menggunakan metode jalur kritis yang dapat membantu:

1. Memberikan informasi untuk mencegah terjadinya keterlambatan

2. Memberikan informasi mengenai toleransi keterlambatan

3. Mengingatkan anggota tim mengenai aktifitas yang due date/batas waktunya sudah dekat.

\section{SARAN}

Berikut ini adalah beberapa saran bagi penelitian selanjutnya.

1. Mengembangkan aplikasi dengan media pengingat selain email, sehingga jika terjadi masalah pada salah satu media, alternatif media dapat digunakan. Sebagai contoh, pengingat menggunakan Short Messaging Service atau SMS.

2. Mengembangkan aplikasi yang mampu menampilkan jalur kritis lebih dari satu rangkaian.

\section{DAFTAR PUSTAKA}

Project Management Institute. 2009. Project Management Body of Knowledge $\left(4^{\text {th }}\right.$ Edition). Project Management Institute. Pennsylvania, USA.

Mosaic Project Services. 2007. The Origins of Modern Project Management. Mosaic Project Services. Melbourne.

Baker, Samuel L. $2004 . \quad$ Critical Path Method (CPM).

http://hspm.sph.sc.edu/COURSES/J716/C PM/CPM.html, diakses 14 Desember 2014).

De Weck, Olivier. 2012. Critical Path Method (CPM) (ocw.mit.edu/.../MITESD_36F12_Lec02.p df, diakses 14 Desember 2014).

Sommerville, Ian. 2011. Software Engineering $\left(9^{\text {th }}\right.$ Edition). Pearson. Boston, Massachusettes, USA.

Solichin, Achmad. 2009. Pemrograman Web dengan PHP dan MySQL. 